\title{
A COMPARATIVE STUDY OF MIDDLE ONE THIRD OF FEMUR SHAFT FRACTURES MANAGED WITH INTERLOCKING NAILS AND KUNTSCHER INTRAMEDULLARY NAILS AT LEVEL 2 AND LEVEL 3 REFERRAL HOSPITALS IN TERMS OF HEALING TIME, FULL WEIGHT BEARING AND POST OPERATIVE COMPLICATIONS
}

\author{
Rakesh Kumar Verma ${ }^{1}$, Ahmer Hasmat ${ }^{2}$, Hetandar Kumar Bhartiya ${ }^{3}$ \\ ${ }^{1}$ Consultant Orthopaedic Surgeon, Department of Orthopaedics, District Hospital, Bahraich, MLN Medical College, Prayagraj, \\ Uttar Pradesh, India. \\ ${ }^{2}$ Assistant Professor, Department of Orthopaedics, MLN Medical College, Prayagraj, Uttar Pradesh, India. \\ 3Senior Resident, Department of Orthopaedics, MLN Medical College, Prayagraj, Uttar Pradesh, India.
}

\section{ABSTRACT}

\section{BACKGROUND}

The aim of the study was to compare the outcome of middle one third of femur shaft fractures managed with Kuntscher intramedullary nails and interlock intramedullary nails at level 2 and level 3 referral hospital in terms of healing time, full weight bearing and post-operative complications.

\section{MATERIALS AND METHODS}

In our quasi experimental study, 100 cases of middle one third femur shaft fractures (Winquist Type I and Type II) were included. Fifty patients were treated with Kuntscher intramedullary nails (Group 1) and rest fifty patient treated with intramedullary Interlocking Nails (Group 2). The detailed data of the patients was recorded, computed and analysed using chi-square test/ Fisher's exact test was plotted using Kaplan Meier performed to compare the study variables between control and study groups. p-value less than $(\mathrm{P}<0.05)$ was taken as statistically significant. The main parameter compared included fracture healing time, full weight bearing time and post-operative complications.

\section{RESULTS}

There was no significant difference between the two groups in terms of demographic data, fracture type and associated comorbidities. The average operating time was $60+10$ minutes for the Kuntscher nail and $110+10$ minutes for interlock nails. Out of 100 fractures 95 (95\%) healed within six months while 5 (5\%) did not. The latter included 1 (1\%) case of delayed union and 3 $(3 \%)$ non-union cases with Kuntscher nail and 1(1\%) in case of interlocking nail.

\section{CONCLUSION}

We therefore conclude that unlocked Kuntscher nailing is still useful for the management of middle one third fracture shaft femur (Winquist type 1 and 2).

\section{KEY WORDS}

Middle One Third Fracture Shaft Femur, Intramedullary Interlock Nail, Kuntscher Nail

HOW TO CITE THIS ARTICLE: Verma RK, Hasmat A, Bhartiya HK. A comparative study of middle one third of femur shaft fractures managed with interlocking nails and Kuntscher intramedullary nails at level 2 and level 3 referral hospitals in terms of healing time, full weight bearing and post-operative complications. J. Evolution Med. Dent. Sci. 2019;8(09):640-643, DOI: $10.14260 /$ jemds/2019/141

\section{BACKGROUND}

Gerhard Kuntscher first introduced unlocked intramedullary nailing for femoral fractures in the 1940's.1,2 The inherent rotational instability of unlocked intramedullary nailing was solved with introduction of the locked intramedullary nail in the 1970's. Winquist RA et al 1989 in their study of a series of intramedullary nailing of femoral fractures concluded that unlocked intramedullary nailing should only be used for the middle one third femoral shaft fractures with Winquist type I or II.

'Financial or Other Competing Interest': None.

Submission 09-01-2019, Peer Review 20-01-2019,

Acceptance 22-01-2019, Published 04-03-2019.

Corresponding Author:

Dr. Hetandar Kumar Bhartiya,

Senior Resident,

Department of Orthopaedics,

MLN Medical College,

Prayagraj, Uttar Pradesh, India.

E-mail: bhartiya.14@gmail.com

DOI: $10.14260 /$ jemds/2019/141
The goal of treatment is restoration of normal anatomy, rigid and stable fixation and early mobilization of hip \& knee joint. $^{3}$

Interlocking Nails are said to control shortening, angulation and rotation, provide early weight bearing but they are expensive and require special instrument and image intensifier. The Kuntscher nails on the other hand are comparatively very cheap, easy to introduce and does not need any special instruments ${ }^{3}$. This study was carried out to compare the intramedullary nailing in our setup.

The aim of the present study is to compare the outcome of middle one third femur shaft fracture managed by Kuntscher intramedullary nail and interlock intramedullary nail at level 2 and level 3 referral hospitals.

\section{MATERIALS AND METHODS}

\section{Design}

Quasi experimental study. 


\section{Study Period}

One and half year, from Jan. 2017 - June 2018.

\section{Sample Size}

The sample size of 100 Patients was taken for convenience.

\section{Sampling}

The patients were selected that came to the emergency Department, in the department of orthopaedics, District Hospital, Bahraich.

\section{Study Population}

For the purpose of study, 100 patients aged between 20-50 years, that are both male and female were selected, which that came to the emergency department of the department of Orthopaedics in the district hospital of Bahraich.

After all the patients were subjected to detailed history, clinical examination, necessary radiological and pathological investigations which are recorded in registers, the patients underwent surgery. All cases were operated in the standard position and procedure of antegrade nailing through pyriformis fossa was followed after adequate reaming of the femoral canal under C-arm fluoroscopy and some cases without fluoroscopy including one pregnant women. The pregnant female was operated in lateral decubitus position on a standard operation table. Fracture fragments were exposed and cleaned with minimum periosteal stripping through lateral approach. The canal was reamed, the nail length was measured with help of reamer passed through canal of both fragments and an appropriately sized Kuntscher nail was inserted retrograde through proximal fragment. The fracture was anatomically reduced under direct vision and nail inserted into the distal fragment by punching. Rotation was corrected using the linea aspera as a marker. The nail was left protruding $2 \mathrm{~cm}$ proximal to the greater trochanter to facilitate its removal.1,2 The wound was closed over a suction drain and was removed after $48 \mathrm{hrs}$. After discharge all the patients were followed up regularly in the outpatient department monthly for 6 months than thrice another 6 months and notice made of any complications, weight bearing time and healing. Bony union was determined by clinical and radiological examinations as the radiological examinations were repeated post operatively and at the end of 6 weeks, 12 weeks and 6 months interval.

\section{Sampling Procedure}

For this study, patients were selected that came with the history of middle one third femur shaft fracture, either from fall, road traffic accident, or assault. These patients were managed alternatively by 2 techniques i.e. Kuntscher nail and Interlocking nail alternatively. So, for intramedullary nailing, 50 cases were operated with Kuntscher nails (Group 1) and 50 cases were managed by interlock intramedullary Nails (Group 2).

\section{Inclusion Criteria}

Patient aged between 20 to 50 years who gave consent to be the part of study.

\section{Statistical Analysis}

Statistical Methods: SPSS version 20 was used for statistical analysis. All study variables were represented using frequency and percentage. Chi-square test / Fisher's exact test was plotted using Kaplan Meier performed to compare the study variables between control and study groups. The $\mathrm{p}-$ value less than $(\mathrm{P}<0.05)$ will be taken as statistically significant.

\section{RESULTS}

In my study, the age (Mean) of the patients was 35 years (2050 years) with $82(82 \%)$ males and 18 (18\%) females. Majority of patients (88\%) sustained fractures following high energy trauma (Road traffic accident), with fall from height (9\%) and assault making up the rest (3\%).

Majority of fractures were on right side ipsilateral 74 (74\%) and left side ipsilateral in 26 (26\%) patients (Table 1). The average operating time was $60+10$ minutes for Kuntscher nail and $110+10$ minutes for interlocking intramedullary nail. 4

All wounds healed with-in 12 days and fractures healed in 16 to 28 weeks for all cases.
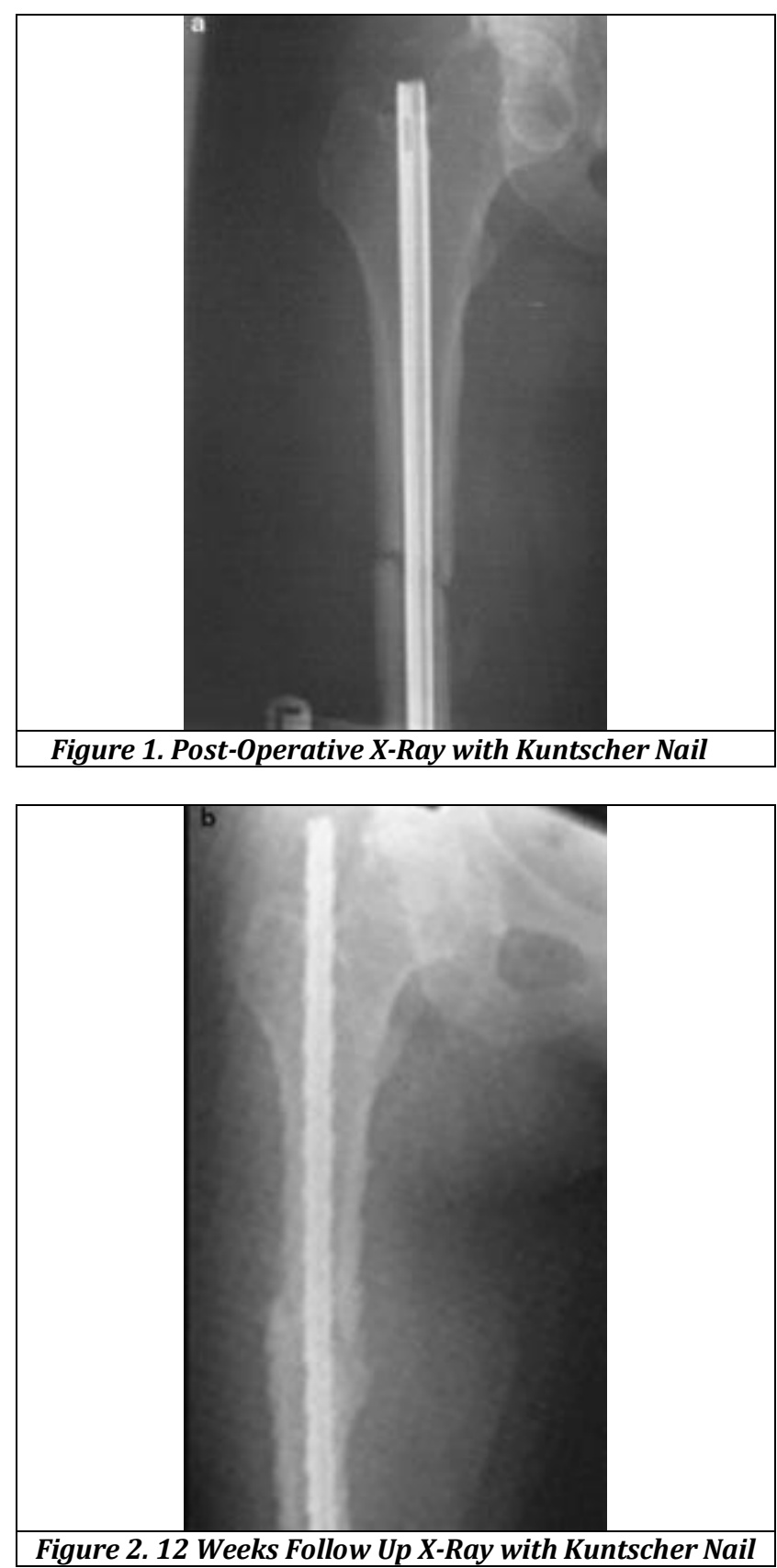

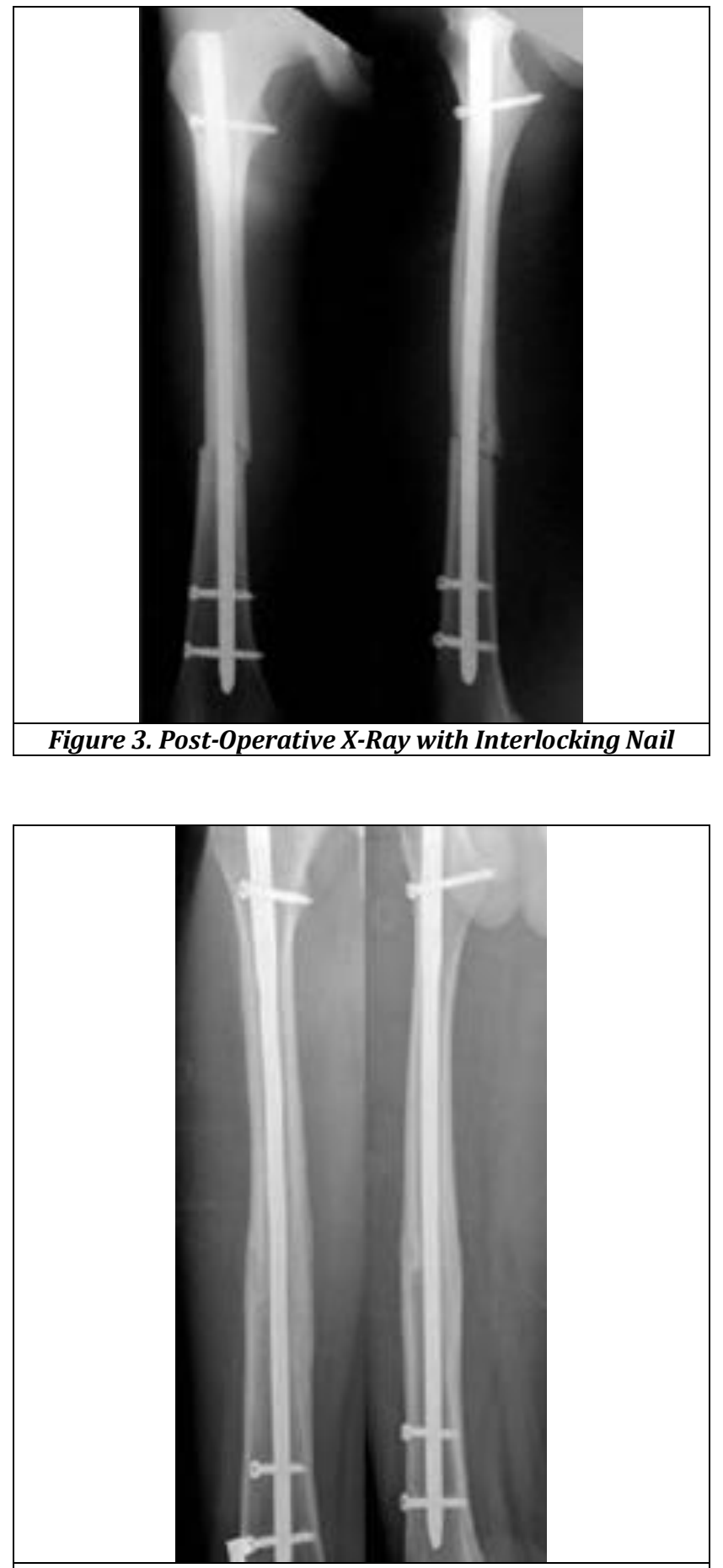

Figure 4. 12 Weeks Follow Up X-Ray with Interlocking Nail

It took 16-24 weeks for fracture healing in case of interlock nail and 16-28 weeks for Kuntscher nails. There were no cases of persistent deep infections. Other main complications were non-union in 4 cases (4\%) and 1 (1\%) delayed union with Kuntscher nail.

Full weight bearing was commenced on the average of 12 to 22 weeks for all fractures, which was 8-16 weeks and 1232 weeks in interlocking nail and Kuntscher nail respectively. The mean average weak of full weight bearing 17 weeks for all cases. The mean average week of full weight bearing was 10 weeks for interlock intramedullary nails and mean average was 14 weeks for Kuntscher nail (Table II).

In our study no patient had a significant limb length discrepancy.

\begin{tabular}{|c|c|c|c|c|}
\hline Sl. No. & Variables & \begin{tabular}{|c|} 
Kuntscher \\
Nail (Group \\
1)
\end{tabular} & \begin{tabular}{|c|} 
Interlock \\
Nail (Group \\
2)
\end{tabular} & p-Value \\
\hline 1. & Sample Size & \begin{tabular}{|l|}
50 \\
\end{tabular} & \begin{tabular}{|l|}
50 \\
\end{tabular} & \\
\hline \multirow{3}{*}{2.} & $\begin{array}{c}\text { Age (Years) } \\
20-30\end{array}$ & 13 & 10 & \multirow{3}{*}{0.5912} \\
\hline & $30-40$ & 28 & 33 & \\
\hline & $40-50$ & 9 & 7 & \\
\hline \multirow[t]{2}{*}{3.} & $\begin{array}{c}\text { Sex } \\
\text { Male }\end{array}$ & 40 & 42 & \multirow{2}{*}{0.6027} \\
\hline & Female & 10 & 8 & \\
\hline \multirow{3}{*}{4.} & $\begin{array}{l}\text { Mode of Injury } \\
\text { Fall }\end{array}$ & 7 & 2 & \multirow{3}{*}{0.1927} \\
\hline & RTA & 42 & 46 & \\
\hline & Blunt Trauma & 1 & 2 & \\
\hline \multirow[t]{2}{*}{5.} & $\begin{array}{c}\text { Side Affected } \\
\text { Right }\end{array}$ & 38 & 36 & \multirow{2}{*}{0.6484} \\
\hline & Left & 12 & 14 & \\
\hline
\end{tabular}

Table I. Demographic Features

*Results are not significant at $5 \%$ level of significance $(\mathrm{P}<0.05)$.

\begin{tabular}{|c|c|c|}
\hline Weeks & $\begin{array}{c}\text { Kuntscher Nail } \\
\text { (Group 1) Sample } \\
50\end{array}$ & $\begin{array}{c}\text { Interlock Nail } \\
\text { (Group 2) Sample } 50\end{array}$ \\
\hline 12 & -- & \\
\hline 14 & -- & \\
\hline 16 & 18 & 23 \\
\hline 18 & -- & 16 \\
\hline 20 & 12 & \\
\hline 22 & 09 & 5 \\
\hline 24 & -- & 5 \\
\hline 26 & -- & \\
\hline 28 & 08 & \\
\hline Total & & \\
\hline $\begin{array}{l}\text { Mean Average } \\
\text { Duration } \\
\end{array}$ & $20.21 \pm 4.26$ & $18.08 \pm 2.71$ \\
\hline
\end{tabular}

\begin{tabular}{|c|c|c|}
\hline Weeks & $\begin{array}{c}\text { Kuntscher Nail } \\
\text { (Group 1) } \\
\text { Sample }=\mathbf{5 0}\end{array}$ & $\begin{array}{c}\text { Interlocking Nail } \\
\text { (Group 2) }\end{array}$ \\
\hline Sample =50 \\
\hline 4 Weeks & --- & --- \\
\hline 8 Weeks & --- & 14 \\
\hline 12 Weeks & 27 & 28 \\
\hline 16 Weeks & 16 & 7 \\
\hline 20 Weeks & 3 & --- \\
\hline 24 Weeks & ----- \\
\hline 28 Weeks & --- & --- \\
\hline 32 Weeks & 1 & 49 \\
\hline Total & 47 & 10.14 weeks \pm 2.19 \\
\hline $\begin{array}{c}\text { Mean Average } \\
\text { Duration }\end{array}$ & 14.30 weeks \pm 3.61 & \multicolumn{2}{|c|}{} \\
\hline $\begin{array}{c}\text { Mean Average } \\
\text { Duration for All } \\
\text { Cases }\end{array}$ & 12.18 weeks \pm 3.62 \\
\hline Table III. Full Weight Bearing Time Duration \\
\hline
\end{tabular}

The Kuntscher nail group 1 and interlock nail group 2 did not differ significantly in their speed of radiological bony union (p-0.7015) or full weight bearing (p-0.4112). Although, the fractures fixed with interlock nail united somewhat earlier as compared to those treated with Kuntscher nail. The difference was not statistically significant. There was no significant difference in post-operative fracture alignment between the two groups. 


\begin{tabular}{|c|c|c|c|}
\hline & $\begin{array}{c}\text { Kuntscher Nail } \\
\text { (Group 1) } \\
\text { Sample of 50 }\end{array}$ & $\begin{array}{c}\text { Interlocking } \\
\text { Nail (Group 2) } \\
\text { Sample of 50 }\end{array}$ & p- Value \\
\hline $\begin{array}{c}\text { Bone Healing } \\
\text { Time }\end{array}$ & $\begin{array}{c}20.21 \text { Weeks } \\
\pm 4.26\end{array}$ & $\begin{array}{c}18.10 \text { Weeks } \\
\pm 2.71\end{array}$ & 0.7015 \\
\hline $\begin{array}{c}\text { Full Weight } \\
\text { Bearing }\end{array}$ & $\begin{array}{c}14.30 \text { Weeks } \\
\pm 3.61\end{array}$ & $\begin{array}{c}10.14 \text { Weeks } \\
\pm 2.19\end{array}$ & 0.4112 \\
\hline $\begin{array}{c}\text { Post-Operative } \\
\text { Complications }\end{array}$ & 4 & 1 & 0.1903 \\
\hline $\begin{array}{c}\text { Overall } \\
\text { Outcome }\end{array}$ & & 0.4996 \\
\hline Table IV. Showing Overall Outcome of The Study in Both \\
The Groups \\
\hline \multicolumn{4}{|c|}{ *Results are not significant at 5\% level of significance. } \\
\hline
\end{tabular}

\section{DISCUSSION}

In the current study, we found that the conventional unlocked intramedullary nail (Kuntscher Nail) is still reliable alternative for Winquist type I and type II fractures of femur, in that there was a rate of $95 \%$ of satisfactory fracture union with an average of 20 weeks. Other studies have shown 12, 16 and 24 weeks in their series. $5,6,4$

This result is comparable to the standard interlock intramedullary nail. Stability of the fixation is not a major concern because the medullary canal is hand reamed to the exact size of the implant diameter and hammered into tight fit canal and convents the compression force into hook stress help to limit rotation instability. Therefore, post-operative rehabilitation is similar to interlock nails. Hence it results in excellent fracture healing early mobility.

The few complications were 5 cases out of which, 4 cases (4\%) went into non-union and 1 case (1\%) went into delayed union in case of Kuntscher nail, while only one case of delayed union was seen in case of interlock nail. The $p$ value was found to be 0.1903 .

Biomechanical studies shows that dynamic implants have more weight bearing capacity than static implants. Furthermore, partial weight bearing creates a micromovements in the dynamic system which increases union rate ${ }^{7}$. The mean average week of full weight bearing is 10 weeks for interlock intramedullary nails and mean average 14 weeks for Kuntscher nail. Other studies report a period of 11 weeks and 14.5 weeks. ${ }^{8}$ The $p$ value was calculated to be 0.4112 .

The fracture healing time in case of Kuntscher Nail was 20 weeks, whereas in case of interlocking intramedullary nail was found to be 18 weeks. The $p$ value was calculated to be 0.7015 . Other studies have shown $\mathrm{p}$ value 0.3282 .4

\section{CONCLUSION}

Femoral nailing has advanced continuously over the past decade. The introduction and increased popularity of interlocking nails allowed for improved rotational control, better maintenance of femoral length, early weight bearing, but even in today's world there exists a large chunk of population who cannot avail of these methods. In a developing country like India, the availability of such techniques and facilities is largely limited to certain centres only.

Many factors are responsible for this scenario like lack of facilities (equipment and trained manpower) \& economic constrains. In such a scenario, close Kuntscher nail is a good option for the treatment of Winquist type I \& type II middle one third femoral fracture, with special indications like pregnant female, in whom exposure of foetus to radiation can be avoided. It provide good union rate and low risk of complications. It is a time saving alternative and results are comparable to closed interlocking intramedullary nailing for this group of fractures. ${ }^{9}$

\section{REFERENCES}

[1] Sage FP. The second decade of experience with Kuntscher medullary nail in the femur. Clin Orthop Relat Res 1968;60:77-85.

[2] Kuntscher GB. The Kuntscher method of intramedullary fixation. J Bone Joint Surg Am 1958;40A(1):17-26.

[3] Winquist RA, Hensen ST. Segmental fracture of the femur treated by closed intramedullary nailing. J Bone Joint Surg Am 1978;60(7):934-9.

[4] Roy RK, Prasad M. Comparative study of Kuntscher nail vs. interlocking nailing for femoral isthmus fractures. J Evid Based Med Healthc 2017;5(41):24502.

[5] Hooper GJ, Lyon DW. Closed unlocked nailing for comminuted femoral fractures. J Bone Joint Surg $\mathrm{Br}$ 1988;70(4):619-21.

[6] Ghosh S, Mondal BC, Chaudhuri A, et al. Study of treatment of short oblique and transverse fractures near isthmus of femur. J Sci Soc 2014;41(2):122-6.

[7] Bankston AB, Keating EM, Saha S. The biomechanical evaluation of intramedullary nails in distal femoral shaft fractures. Clin Orthop Related Res 1992;(276)277-82.

[8] Baixauli F Sr, Baixauli EJ, Sanchez-Alepuz E, et al. Interlocked intramedullary nailing for treatment of open femoral shaft fractures. Clin Orthop Related Res 1998;(350):67-73.

[9] Bellabara C, Ricci WM, Bolhofner BR. Results of indirect reduction and plating of femoral shaft nonunion after intramedullary nailing. J Orthop Trauma 2001;15(4):254-63. 